\title{
Contributions of Gluconeogenesis to Glucose Production in the Fasted State
}

\author{
Bernard R. Landau, ${ }^{\star \ddagger}$ John Wahren, Visvanathan Chandramouli, ${ }^{*}$ William C. Schumann, ${ }^{*}$ Karin Ekberg, \\ and Satish C. Kalhan $\$$ \\ Departments of *Medicine, ${ }^{*}$ Biochemistry and ${ }^{\S}$ Pediatrics, Case Western Reserve University School of Medicine, Cleveland, Ohio 44106; \\ and ${ }^{\|}$Department of Clinical Physiology, Karolinska Hospital, S 17176 Stockholm, Sweden
}

\begin{abstract}
Healthy subjects ingested ${ }^{2} \mathrm{H}_{2} \mathrm{O}$ and after 14, 22, and $42 \mathrm{~h}$ of fasting the enrichments of deuterium in the hydrogens bound to carbons 2, 5, and 6 of blood glucose and in body water were determined. The hydrogens bound to the carbons were isolated in formaldehyde which was converted to hexamethylenetetramine for assay. Enrichment of the deuterium bound to carbon 5 of glucose to that in water or to carbon 2 directly equals the fraction of glucose formed by gluconeogenesis. The contribution of gluconeogenesis to glucose production was $47 \pm 4 \%$ after $14 \mathrm{~h}, 67 \pm 4 \%$ after $22 \mathrm{~h}$, and $93 \pm 2 \%$ after $42 \mathrm{~h}$ of fasting. Glycerol's conversion to glucose is included in estimates using the enrichment at carbon 5 , but not carbon 6 . Equilibrations with water of the hydrogens bound to carbon 3 of pyruvate that become those bound to carbon 6 of glucose and of the hydrogen at carbon 2 of glucose produced via glycogenolysis are estimated from the enrichments to be $\sim 80 \%$ complete. Thus, rates of gluconeogenesis can be determined without corrections required in other tracer methodologies. After an overnight fast gluconeogenesis accounts for $\sim 50 \%$ and after $42 \mathrm{~h}$ of fasting for almost all of glucose production in healthy subjects. (J. Clin. Invest. 1996. 98:378-385.) Key words: fasting • deuterium oxide $\bullet$ glucose $\bullet$ glycogen $\bullet$ gluconeogenesis
\end{abstract}

\section{Introduction}

We recently introduced a method for estimating contributions of gluconeogenesis to glucose production (1). Estimates depended upon the extent of enrichment of deuterium in the hydrogen bound to carbon 6 of glucose after ingestion of ${ }^{2} \mathrm{H}_{2} \mathrm{O}$. In the conversion of pyruvate to glucose the hydrogens bound to carbon 3 of pyruvate exchange with hydrogen in water and it is that carbon, with two bound hydrogens, that becomes carbon 6 of glucose. Oxidation of the glucose with periodic acid yields formaldehyde containing carbon 6 and the hydrogens. A strength of the method is in the use of hexamethylenetetramine (HMT) ${ }^{1}{ }^{1} \mathrm{C}_{6} \mathrm{H}_{12} \mathrm{~N}_{4}$, a condensation product of six mole-

Address correspondence to Bernard R. Landau, Ph.D., M.D., Department of Medicine, Case Western Reserve University School of Medicine, 10900 Euclid Ave., Cleveland, OH 44106-4951. Phone: 216-368-4958; FAX: 216-368-4927.

Received for publication 5 February 1996 and accepted in revised form 8 May 1996.

1. Abbreviation used in this paper: HMT, hexamethylenetetramine.

J. Clin. Invest.

(c) The American Society for Clinical Investigation, Inc. 0021-9738/96/07/0378/08 \$2.00

Volume 98, Number 2, July 1996, 378-385 cules of formaldehyde and four molecules of $\mathrm{NH}_{3}$, to assay the enrichment of the hydrogens. All 12 hydrogens of HMT are from the formaldehyde. That magnification allows for an accurate measurement of enrichment, while giving a safe, well-tolerated dose of ${ }^{2} \mathrm{H}_{2} \mathrm{O}$.

Enrichment of the hydrogens bound to carbon 6 of blood glucose should equal that in body water, if all glucose formation is via gluconeogenesis from pyruvate, the exchange is complete, and the enrichment has reached steady state. Since in the conversion of glycogen to glucose the hydrogens bound to carbon 6 do not exchange with hydrogen in water, the fraction of blood glucose formed by gluconeogenesis is then the ratio of the enrichment of deuterium in a hydrogen bound to carbon 6 of glucose to that in body water (1). Since in gluconeogenesis, fructose-6-P $\Leftrightarrow$ glucose-6-P $\rightarrow$ glucose, the enrichment of the hydrogen bound to carbon 2 of blood glucose formed by gluconeogenesis should also be about that in body water. The hydrogen bound to carbon 2 of glucose formed by glycogenolysis should also have about the same enrichment as in body water, since as glycogen $\rightarrow$ glucose- $6-\mathrm{P} \rightarrow$ glucose, there is extensive isomerization of glucose-6-P with fructose6-P (2). Thus, after ${ }^{2} \mathrm{H}_{2} \mathrm{O}$ ingestion, the enrichment of a hydrogen bound to carbon 6 to that bound to carbon 2 of blood glucose also measures the fraction of the glucose formed by gluconeogenesis.

However, reliance on enrichment of the hydrogen bound to carbon 6 results in underestimates. The exchange of the hydrogens bound to carbon 3 of pyruvate with those in water is extensive, but incomplete (1). Also, gluconeogenesis from glycerol is not measured, since the hydrogens bound to carbon 3 of glycerol that become the hydrogens bound to carbon 6 of glucose do not exchange with hydrogen in body water. We now apply an approach which removes those limitations.

The approach rests on the fact that hydrogen bound to carbon 5 of glucose formed via gluconeogenesis, in the conversion of phosphoenolpyruvate to 2-phosphoglyceric acid, has water as its source. Furthermore, when glycerol is converted to glucose, carbon 5 of the glucose is from carbon 2 of glyceraldehyde-3-P (Fig. 1). Hydrogen from water is transferred to that carbon in the isomerization of dihydroxyacetone-3-P from the glycerol with glyceraldehyde-3-P, and that isomerization is extensive (3). In glycogenolysis there is no exchange with water of the hydrogen bound to carbon 5 of the glucose formed. Thus, the ratio of enrichment at carbon 5 of glucose to that at carbon 2, or in water at steady state, is a direct measure of the fraction of glucose formed by gluconeogenesis.

We chemically converted glucose to xylose by the removal of carbon 6. Oxidation of the xylose with periodic acid then yields formaldehyde containing carbon 5 of glucose with its bound hydrogen. Determination of the enrichment at carbon 2 of glucose using a lactate derivative (1), while adequate, does not have the advantage provided by using HMT. Therefore, we also developed a procedure that yields formaldehyde with 


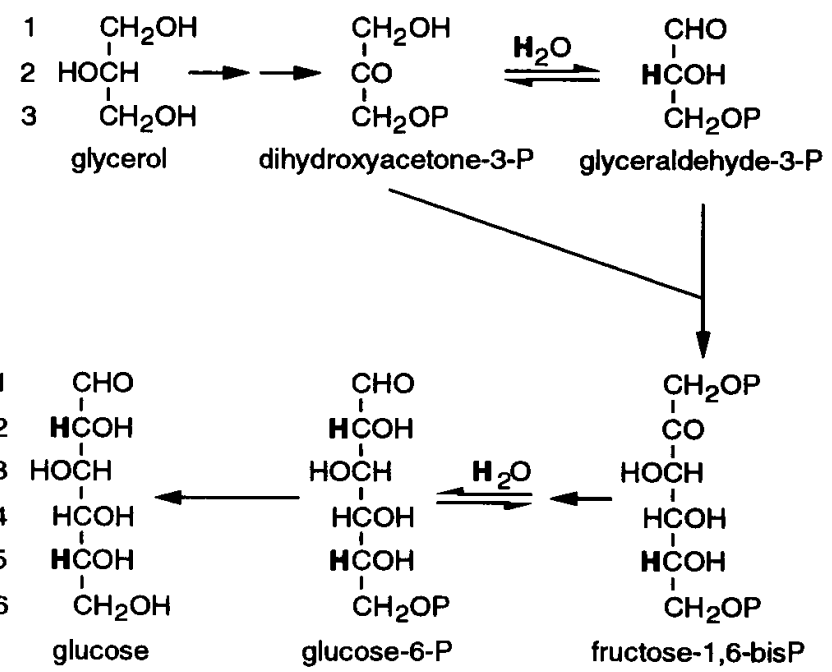

Figure 1. Glycerol conversion to glucose and the site of labeling at carbons 2 and 5 of the glucose by deuterium (bold hydrogen) from deuterated water.

the hydrogen bound to carbon 2 of glucose and hence a HMT containing that hydrogen.

There has been uncertainty with regard to the contribution of gluconeogenesis during fasting. Healthy subjects were given ${ }^{2} \mathrm{H}_{2} \mathrm{O}$ and fasted for $42 \mathrm{~h}$. At timed intervals during the fast the enrichments at carbons 2, 5, and 6 of glucose using the HMT derivative were determined. Enrichment in urinary water was the measure of the enrichment in body water. From the ratios of enrichments estimates were made of the fraction of glucose produced by gluconeogenesis. The ratios also give a measure of the extent of exchange of the hydrogens of pyruvate that results in the enrichment at carbon 6 and the extent of isomerization of the hexose-6-phosphates that results in the enrichment at carbon 2 in the process of glycogenolysis.

\section{Methods}

Subjects. Eight healthy subjects, six women and two men, ages 24 to $39 \mathrm{yr}(31.3 \pm 1.9)$ were studied. Their weights ranged from 63 to $86 \mathrm{~kg}$ (body mass index $23.4 \pm 0.5 \mathrm{~kg} / \mathrm{m}^{2}$ ). As recorded in dietary diaries, they ingested at least 200 grams of carbohydrate daily for the $4 \mathrm{~d}$ before study. They reported no change in diet and weight during the prior months.
Experimental protocol. The protocol was that used previously (1). At 5 p.m. on the day of the study the subjects ingested during $1 \mathrm{~h}$ a meal of 12-14 kcal per kg of body weight and composed of $48 \%$ carbohydrate, $19 \%$ protein, and $33 \%$ fat. They then fasted for $42 \mathrm{~h}$ except for water ingestion. $5 \mathrm{~h}$ after beginning the fast they drank 2.5 grams of ${ }^{2} \mathrm{H}_{2} \mathrm{O}\left(99.9 \%{ }^{2} \mathrm{H}\right.$, ISOTEC, Miamisburg, OH) per $\mathrm{kg}$ of body water and $4 \mathrm{~h}$ later another 2.5 grams of the ${ }^{2} \mathrm{H}_{2} \mathrm{O}$ per kg body water. Body water was calculated to be $50 \%$ of body weight in women and $60 \%$ in men. Water they ingested ad libitum throughout the fast was enriched to $0.5 \%$ with ${ }^{2} \mathrm{H}_{2} \mathrm{O}$ to maintain isotopic steady state. Peripheral vein blood was drawn at 14,22 , and $42 \mathrm{~h}$ into the fast. Urine was collected in most of the subjects at $14-18$ and $38-42 \mathrm{~h}$.

Analytical procedures. Glucose concentration in plasma was determined using glucose oxidase (Beckman Instruments, Inc., Fullerton, CA) and beta-hydroxybutyrate in blood using beta-hydroxybutyrate dehydrogenase (4). Enrichment in urine was determined by Dr. David Wagner (Metabolic Solutions, Inc., Merrimack, NH) using an isotope ratio mass spectrometer with urines of known enrichments from 0.25 to $0.75 \%$ providing a standard curve. Along with urines from the subjects, samples of known enrichment were sent to that laboratory as controls and the enrichment reported for those samples were within $1 \%$ of the actual enrichments. Urines were distilled and the distillates gave the same enrichment as the urines, providing further confidence in the reliability of the assays.

Glucose conversion to xylose. Glucose was isolated by HPLC of a deionized solution from $\mathrm{Ba}(\mathrm{OH})_{2}$ and $\mathrm{ZnSO}_{4}$ deproteinized blood, as previously detailed (1). The procedure for converting glucose to xylose (Fig. 2) was a small scale modification of that used to synthesize $\left(1-{ }^{14} \mathrm{C}\right) x y$ lose from $\left(1-{ }^{14} \mathrm{C}\right)$ glucose $(5) .5 \mathrm{mg}$ of glucose in $1 \mathrm{ml}$ of acetone containing $0.04 \mathrm{ml}$ of concentrated $\mathrm{H}_{2} \mathrm{SO}_{4}$ was stirred at room temperature for $4 \mathrm{~h}$. The mixture was made just alkaline by the addition of $10 \mathrm{~N} \mathrm{NaOH}$ and filtered. The $\mathrm{Na}_{2} \mathrm{SO}_{4}$ cake was washed with acetone and the combined filtrates evaporated to dryness. $1 \mathrm{ml}$ of $0.01 \mathrm{~N} \mathrm{HCl}$ was added to the residue, giving a $\mathrm{pH}$ near 2, and the solution was stirred at $40^{\circ} \mathrm{C}$ for $5 \mathrm{~h}$. The solution was adjusted to $\mathrm{pH} 8$ by the addition of $0.1 \mathrm{~N} \mathrm{NaOH}$ and extracted with $3 \mathrm{ml} \times 3$ of ethyl acetate to remove unchanged diacetone glucose. A drop of methyl red indicator, $0.04 \%$ in $60 \%$ ethanol, and $10 \mathrm{mg}$ of sodium periodate were added to the aqueous solution and the $\mathrm{pH}$ was adjusted to about 5 by the addition of $0.01 \mathrm{~N} \mathrm{NaOH}$. After $1 \mathrm{~h}$ at room temperature the solution was evaporated in vacuo to dryness and $20 \mathrm{mg}$ of anhydrous sodium sulfate was added to the residue to complete drying.

The aldomonoacetone xylose in the residue was extracted into $3 \times 2 \mathrm{ml}$ of chloroform. The chloroform was filtered through a plug of anhydrous sodium sulfate and evaporated to dryness. The residue was dissolved in $1 \mathrm{ml}$ of water and $20 \mathrm{mg}$ of $\mathrm{NaBH}_{4}$ was added. After $30 \mathrm{~min}$ at room temperature excess borohydride was destroyed by the drop-wise addition of $1 \mathrm{~N} \mathrm{HCl}$. The solution was evaporated to dryness and $5 \mathrm{ml}$ of methanol was added and evaporated to remove borate as methyl borate. Addition of $5 \mathrm{ml}$ of methanol and its evaporation was repeated twice more. The residue after the addition of $1 \mathrm{ml}$

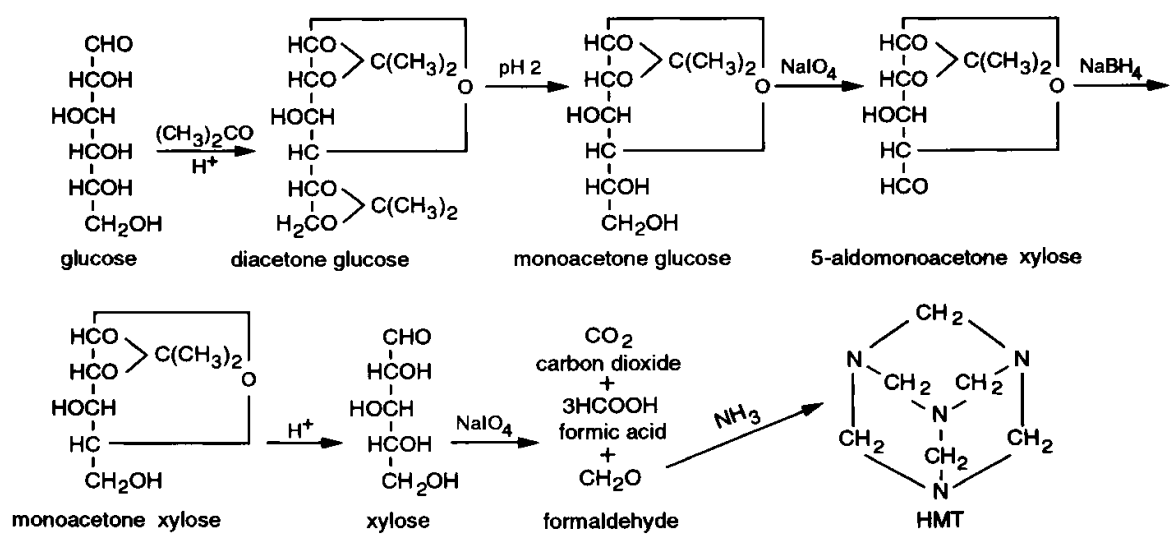

Figure 2. Conversion of glucose to xylose and the formation of HMT from formaldehyde from xylose. 

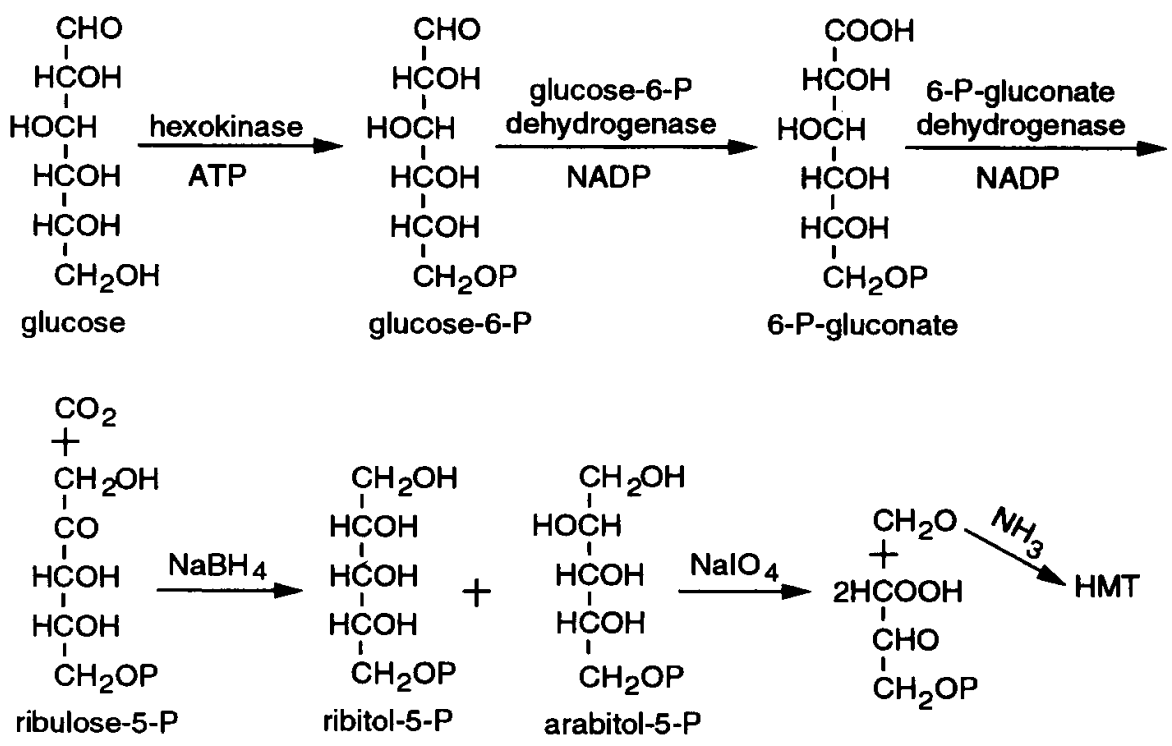

Figure 3. Conversion of glucose to polyol phosphates and the formation of HMT from formaldehyde from the phosphates. of $0.1 \mathrm{~N} \mathrm{H}_{2} \mathrm{SO}_{4}$ was placed in a boiling water bath for $1 \mathrm{~h}$ to hydrolyze the monoacetone xylose to xylose. The hydrolysate was passed through a column of 1.5 grams AG $50 \mathrm{~W}-\mathrm{X} 8$ in the hydrogen form over 1.5 grams AG 1-X8 in the formate form (Bio-Rad Labs, Hercules, CA). The column was washed with water and the effluent evaporated to dryness.

The xylose was purified by HPLC using a Bio-Rad HPX-87P column with water as solvent at $80^{\circ} \mathrm{C}$ and a flow rate of $0.5 \mathrm{ml} / \mathrm{min}$. Xylose eluted at $16-18 \mathrm{~min}$. The amount of xylose in the eluate was determined by the Dische method (6). The yield from glucose was $40-45 \%$ of theoretical. A similar yield was obtained beginning with $2 \mathrm{mg}$ of glucose. An adequate yield of xylose for preparation of HMT has been obtained beginning with only $0.7 \mathrm{mg}$ of glucose. In accord with the removal of carbon 6 , when $\left(6-{ }^{3} \mathrm{H}, 1-{ }^{14} \mathrm{C}\right)$ glucose was converted to xylose, $99 \%$ of the ${ }^{3} \mathrm{H}$ was lost relative to ${ }^{14} \mathrm{C}$, and when an HMT was prepared from xylose from $\left(6-{ }^{3} \mathrm{H}, 5-{ }^{14} \mathrm{C}\right)$ glucose $>99 \%$ of the ${ }^{3} \mathrm{H}$ was lost relative to ${ }^{14} \mathrm{C}$ and from $\left(5-{ }^{3} \mathrm{H}, 6-{ }^{14} \mathrm{C}\right)$ glucose $98 \%$ of the ${ }^{14} \mathrm{C}$ was lost relative to ${ }^{3} \mathrm{H}$. The ${ }^{3} \mathrm{H} /{ }^{14} \mathrm{C}$ ratio in the HMT from $\left(5_{-}{ }^{3} \mathrm{H}, 5-\right.$ ${ }^{14} \mathrm{C}$ )glucose was the same as in the glucose, indicating no loss of the hydrogen and no isotope effect. The $\left(1-{ }^{14} \mathrm{C}\right)$ glucose, $\left(6-{ }^{14} \mathrm{C}\right)$ glucose, $\left(5-{ }^{3} \mathrm{H}\right)$ glucose, and $\left(6-{ }^{3} \mathrm{H}\right)$ glucose were purchased commercially and the $\left(5-{ }^{14} \mathrm{C}\right)$ glucose was synthesized (7).

Glucose conversion to ribitol-5-P and arabitol-5-P (Fig. 3). The conversion of glucose to ribulose-5-P was essentially as described $(8,9)$. The reactions were taken to completion by coupling them to the conversion of $\alpha$-ketoglutarate to glutamate. The reduction of the ribulose-5-P to the polyol phosphates was done by a microscale modification of the method described in references 10 and 11 (Fig. 3). $2 \mathrm{mg}$ of glucose was incubated for $1 \mathrm{~h}$ at $30^{\circ} \mathrm{C}$ in $1 \mathrm{ml}$ of $0.1 \mathrm{M}$ triethanolamine buffer, pH 7.6, with $10 \mathrm{mM} \mathrm{MgCl}_{2}, 8 \mathrm{mg}$ of ATP, and $4 \mathrm{U}$ of hexokinase. Conversion of the glucose to glucose-6-P was virtually complete as evidenced by retention on an anion exchange column of all the ${ }^{14} \mathrm{C}$ when an incubate in which the glucose had been labeled with $\left(1-{ }^{14} \mathrm{C}\right)$ glucose was passed through the column. After $1 \mathrm{~h}, 5 \mathrm{mg}$ of $\alpha$-ketoglutarate, $2 \mathrm{mg}$ of $\mathrm{NH}_{4} \mathrm{Cl}, 6 \mathrm{mg}$ of NADP, $1 \mathrm{U}$ of glucose-6-P dehydrogenase, $1 \mathrm{U}$ of 6 phosphogluconate dehydrogenase, and $1.5 \mathrm{U}$ of glutamate dehydrogenase were added, giving a total volume of incubate of $1.2 \mathrm{ml}$ (all enzymes and nucleotides were purchased from Sigma Chemical Co., St. Louis, MO). The $\mathrm{pH}$ was adjusted to 7.7, requiring a small amount, $\sim 0.1 \mathrm{ml}$, of $1 \mathrm{~N} \mathrm{NaOH}$ and the incubation continued for an additional $3 \mathrm{~h}$ at $30^{\circ} \mathrm{C}$.

To stop the reaction $0.1 \mathrm{ml}$ of $50 \%$ trichloroacetic acid was added and then a pinch of activated charcoal to absorb the nucleotides (12). The mixture was centrifuged, another pinch of the charcoal added to the supernatant, and the resulting mixture again centrifuged. The re- moval of the nucleotides from solution was followed by the disappearance of absorption at $260 \mathrm{mu}$. The supernatant was extracted with ether $(2 \mathrm{ml} \times 3)$ to remove trichloroacetic acid. It was then passed through the AG 1-X8 ion exchange column in the formate form. The column was washed with water, and then the ribulose-5-P was eluted with $1 \mathrm{~N}$ formic acid. That fraction was evaporated to dryness.

When $\left(2-{ }^{3} \mathrm{H}, 1-{ }^{14} \mathrm{C}\right)$ glucose was carried through to this stage of the procedure $\sim 60 \%$ of the ${ }^{3} \mathrm{H}$ in the glucose was recovered in the $1 \mathrm{~N}$ formic acid fraction. The amount of ketopentose in the fraction, determined using the Dische colorimetric assay (6), was also $\sim 60 \%$ of theoretical. After treatment with phosphatase, on HPLC using the HPX-87P column, there was a single radioactive peak with the mobility of ribulose, giving the color described for a ketopentose (6). While the amount of ribose-5-P isomerase in the enzyme preparation used was reported to be $<0.03 \%$, we were concerned about ribose-5-P as a contaminant. However, there was no evidence of contamination on HPLC, the hydrogen lost in the isomerization of ribulose-5-P to ribose-5-P is not the hydrogen bound to carbon 2 of the glucose, and reduction of ribose-5-P also yields ribitol-5-P.

The ribulose-5-P was dissolved in $0.3 \mathrm{ml}$ of water, the solution taken to $\mathrm{pH} 7$ with $\mathrm{NaOH}$, and $2 \mathrm{mg}$ of $\mathrm{NaBH}_{4}$ was added. After $12 \mathrm{~h}$ at room temperature $0.08 \mathrm{ml}$ of $2 \mathrm{~N}$ acetic acid followed by $0.05 \mathrm{ml}$ of $7 \mathrm{M} \mathrm{NH}_{4} \mathrm{OH}$ was added, giving a $\mathrm{pH}$ of 8-9. The solution was diluted to $2 \mathrm{ml}$ with water and passed through a $1 \mathrm{ml}$ column of the AG 1-X8 resin in the acetate form. The column was washed with water and then the polyol phosphates eluted in about $2 \mathrm{ml}$ of $1 \mathrm{~N}$ ammonium acetate. Cations were removed from the eluate by adding 2-3 grams of AG-50W in the $\mathrm{H}^{+}$form. The supernatant combined with water washings of the resin was evaporated at room temperature with additions of water to remove acetic acid, and then evaporated to dryness. Traces of borate were removed by addition and evaporation of methanol $(2 \mathrm{ml} \times 3)$.

The yield of polyol phosphates from the glucose was $\sim 30 \%$ of theoretical. That yield is based on recovery of ${ }^{3} \mathrm{H}$ beginning with $\left(2-{ }^{3} \mathrm{H}\right)$ glucose. After phosphatase treatment, two peaks with about equal radioactivity were found on HPLC using the HPX-87P column, one with the mobility of ribitol and the other with that of arabitol. An HMT prepared from the polyol phosphates obtained on incubation of $\left(2-{ }^{3} \mathrm{H}, 2-{ }^{14} \mathrm{C}\right)$ glucose had the same ${ }^{3} \mathrm{H} /{ }^{14} \mathrm{C}$ ratio as the glucose. When $\left(2-{ }^{3} \mathrm{H}, 1-{ }^{14} \mathrm{C}\right)$ glucose was incubated, HMTs had $<2 \%$ of the ${ }^{14} \mathrm{C}$ relative to ${ }^{3} \mathrm{H}$ in the glucose, in accord with the removal of carbon 1 . An HMT, when $\left(2-{ }^{3} \mathrm{H}, 6{ }^{-14} \mathrm{C}\right)$ glucose was incubated, had $<0.5 \%$ of ${ }^{14} \mathrm{C}$ relative ${ }^{3} \mathrm{H}$ in the glucose, in accord with no formaldehyde being formed on periodic acid oxidation from position 6 of glucose when 
phosphorylated. The failure to form an HMT and hence formaldehyde on periodic acid oxidation of glucose-6-P was also confirmed.

Preparation and assay of the HMT. The procedure for preparing HMT from xylose and the polyol phosphates was the same as previously detailed for glucose, except we now use for periodate oxidation the conditions of Reeves (13). The oxidation is then completed in $1 \mathrm{~h}$ rather than overnight. To the sugar or sugar phosphates in $0.1 \mathrm{ml}$ of water, $0.2 \mathrm{ml}$ of $0.3 \mathrm{M}$ periodic acid and $0.2 \mathrm{ml}$ of $1 \mathrm{~N}$ sodium bicarbonate were added. After $1 \mathrm{~h}$ at room temperature, $0.3 \mathrm{ml}$ of $1 \mathrm{~N} \mathrm{HCl}$ and $0.2 \mathrm{ml}$ of $1.2 \mathrm{~N}$ sodium arsenite were added to destroy excess periodate. After the iodine color disappeared the solution was made basic to phenol red by the addition of $0.03 \mathrm{ml}$ of $10 \mathrm{~N} \mathrm{NaOH}$ and distilled. $1.5 \mathrm{ml}$ of $7 \mathrm{M} \mathrm{NH}_{4} \mathrm{OH}$ was added to the distillate. The solution after remaining at room temperature overnight was evaporated to dryness. The HMT in the residue was then assayed for deuterium enrichment by mass spectrometry as previously detailed $(1,14)$.

Usually $0.4-0.7 \mathrm{mg}$ of glucose, xylose, or the polyol phosphates was oxidized. However, $0.2 \mathrm{mg}$ of glucose or xylose gives sufficient HMT for several repeat assays of ${ }^{2} \mathrm{H}$ enrichment (14). The yields of HMT from xylose and glucose were $\sim 40 \%$ of theoretical, but from the polyol phosphates only $\sim 30 \%$. Ribulose-5-P, prepared from $\left(2-{ }^{3} \mathrm{H}\right.$, $\left.2-{ }^{14} \mathrm{C}\right)$ glucose, gave an HMT on periodic acid oxidation with the same ratio of label as periodic acid oxidation of polyol phosphates formed from the glucose. However, yields from ribulose-5-P were less, 10$15 \%$, probably because a hydroxyketo group rather than a dihydroxy group was cleaved (15).

Enrichment in HMTs from carbons 2, 5, and 6 of a blood glucose, prepared in singleton, were determined by mass spectrometry at the same sitting. No HMTs of known ${ }^{2} \mathrm{H}$ enrichment had to be assayed in order to determine absolute enrichment, since the ratio of the peaks of $\mathrm{m}+1$ (mass 141) of the HMTs from carbons 2, 5, and 6 above background were equivalent to the ratios of their absolute enrichments. However, at each sitting HMTs from formaldehyde of 0.125 , $0.25,0.5$, and $1.0 \%{ }^{2} \mathrm{H}$ enrichment, prepared from $\left(1-{ }^{2} \mathrm{H}_{1}\right)$ sorbitol as previously detailed $(1,14)$, were also assayed. That allowed the absolute enrichments of the hydrogens bound to the carbons to be compared with the enrichment in urinary water. Background was measured on HMTs prepared from blood glucose from subjects before ingesting ${ }^{2} \mathrm{H}_{2} \mathrm{O}$.

As further support for the procedures, HMTs from formaldehydes from polyol phosphates formed from $\left(2{ }^{2} \mathrm{H}\right)$ glucose of 0.25 , 0.50 , and $1.0 \%$ enrichments and from xylose prepared from $\left({ }^{2} \mathrm{H}_{7}\right)$ glucose of $0.25,0.50$, and $1.0 \%$ enrichments gave the same readings as the corresponding HMTs form $\left(1-{ }^{2} \mathrm{H}_{1}\right)$ sorbitol. The readings of the sorbitol standards varied very little from sitting to sitting. The $\left(1-^{2} \mathrm{H}\right)$ glucose used to prepare the $\left(1-{ }^{2} \mathrm{H}_{1}\right)$ sorbitol, the $\left(2-{ }^{2} \mathrm{H}\right)$ glucose, and $\left({ }^{2} \mathrm{H}_{7}\right)$ glucose were purchased from Cambridge Isotope Laboratories (Andover, MA).

Calculations. The enrichment in the HMT from carbon 6 of glucose was divided by two because there are two hydrogens bound to carbon 6 that are enriched. The enrichments in the HMTs from formaldehyde from xylose and the polyol phosphates were those in the hydrogens bound, respectively, to carbons 5 and 2 of the glucose. That is because the source of one of the two hydrogens bound to the formaldehyde carbon 5 was $\mathrm{NaBH}_{4}$ and the source of one of the two hydrogens bound to formaldehyde carbon $2 \mathrm{was} \mathrm{a}^{+}$in the incubation medium. The fraction of blood glucose produced due to gluconeogenesis was calculated by dividing the enrichment at carbon 5 at 14,22 , and $42 \mathrm{~h}$ by that at carbon 2 at $42 \mathrm{~h}$ of fasting. The assumption that at $42 \mathrm{~h}$ the enrichment at carbon 2 was essentially that in body water was tested by the ratios of those enrichments. The ratio of enrichments at carbon 2 at 14 and $22 \mathrm{~h}$ to that at carbon 2 at $42 \mathrm{~h}$ was calculated to provide an estimate of the extent of equilibration of glucose-6-P with fructose-6-P during glycogenolysis. The enrichment at carbon 6 to carbon 2 was calculated to give an estimate of the fraction of glucose production via gluconeogenesis from pyruvate (1). The difference between that fraction and the fraction calculated from the carbon 5 to carbon 2 ratio provided a measure of the contribution of glycerol to
Table I. Enrichment in Deuterium in Hydrogens at Carbons 2, 5, and 6 of Blood Glucose and in Urinary Water

\begin{tabular}{|c|c|c|c|c|c|}
\hline \multirow[b]{2}{*}{ Subject } & \multirow[b]{2}{*}{ Time } & \multicolumn{3}{|c|}{ Percent ${ }^{2} \mathrm{H}$ enrichment at blood glucose } & \multirow[b]{2}{*}{ Urinary water* } \\
\hline & & Carbon 2 & Carbon 5 & Carbon 6 & \\
\hline & $h$ & & & & \\
\hline \multirow[t]{3}{*}{ EF } & 14 & 0.414 & 0.178 & 0.113 & 0.444 \\
\hline & 22 & 0.422 & 0.284 & 0.185 & \\
\hline & 42 & 0.457 & 0.416 & 0.339 & 0.437 \\
\hline \multirow[t]{3}{*}{ TA } & 14 & 0.376 & 0.274 & 0.180 & \\
\hline & 22 & 0.416 & 0.347 & 0.238 & \\
\hline & 42 & 0.437 & 0.433 & 0.315 & 0.443 \\
\hline \multirow[t]{3}{*}{ CS } & 14 & 0.418 & 0.289 & 0.188 & 0.510 \\
\hline & 22 & 0.429 & 0.360 & 0.244 & \\
\hline & 42 & 0.461 & 0.386 & 0.322 & 0.491 \\
\hline \multirow[t]{3}{*}{ MB } & 14 & 0.438 & 0.268 & 0.196 & \\
\hline & 22 & 0.469 & 0.409 & 0.276 & \\
\hline & 42 & 0.507 & 0.469 & 0.370 & \\
\hline \multirow[t]{3}{*}{$\mathrm{AM}$} & 14 & 0.438 & 0.162 & 0.110 & \\
\hline & 22 & 0.486 & 0.260 & 0.181 & \\
\hline & 42 & 0.494 & 0.492 & 0.345 & \\
\hline \multirow[t]{3}{*}{$\mathrm{HH}$} & 14 & 0.412 & 0.151 & 0.102 & 0.417 \\
\hline & 22 & 0.427 & 0.274 & 0.195 & \\
\hline & 42 & 0.417 & 0.386 & 0.265 & 0.420 \\
\hline \multirow[t]{3}{*}{$\mathrm{JC}$} & 14 & 0.324 & 0.222 & 0.162 & 0.419 \\
\hline & 22 & 0.407 & 0.324 & 0.224 & \\
\hline & 42 & 0.456 & 0.438 & 0.341 & 0.439 \\
\hline \multirow[t]{3}{*}{ EL } & 14 & 0.452 & 0.248 & 0.165 & 0.473 \\
\hline & 22 & 0.440 & 0.283 & 0.182 & \\
\hline & 42 & 0.464 & 0.433 & 0.308 & 0.454 \\
\hline
\end{tabular}

*Enrichment recorded at $14 \mathrm{~h}$ is that in urine collected from $14-18 \mathrm{~h}$ and at $42 \mathrm{~h}$ in urine collected from $38-42 \mathrm{~h}$.

gluconeogenesis and the equilibration of the hydrogens in pyruvate with those of body water during the course of gluconeogenesis. Means \pm standard errors of the means were calculated.

\section{Results}

Plasma glucose concentration was $5.2 \pm 0.1 \mathrm{mM}$ after $14 \mathrm{~h}$ and $4.3 \pm 0.1 \mathrm{mM}$ after $42 \mathrm{~h}$ of fasting. Blood beta-hydroxybutyrate concentration was $76 \pm 25 \mu \mathrm{M}$ at $14 \mathrm{~h}$ and $1127 \pm 153 \mu \mathrm{M}$ at $42 \mathrm{~h}$.

The enrichments of the hydrogens at carbons 2,5 , and 6 of blood glucose and in urinary water from the eight subjects are recorded in Table I and the ratios of those enrichments in Table II. The ratio of enrichment at carbon 5 at $14 \mathrm{~h}$ to that at carbon 2 at $42 \mathrm{~h}$ was $0.49 \pm 0.04$ (Table II), meaning the percentage of glucose production due to gluconeogenesis after $14 \mathrm{~h}$ varied, but was $\sim 50 \%$. The ratio of the enrichment at carbon 5 at $22 \mathrm{~h}$ to that at carbon 2 at $42 \mathrm{~h}$ gives an estimated gluconeogenesis contribution at $22 \mathrm{~h}$ of $69 \pm 4 \%$. The corresponding ratio at $42 \mathrm{~h}$ indicates a contribution of $94 \pm 2 \%$.

In glycogenolysis $\sim 10 \%$ of the glucose released arises from the hydrolysis of the branch points in the glycogen, i.e., without glucose-6-P as an intermediate. That glucose would 
Table II. Ratios of Enrichments in Table I

\begin{tabular}{|c|c|c|c|c|c|}
\hline \multirow[b]{2}{*}{ Subject } & \multirow[b]{2}{*}{ Time } & \multirow{2}{*}{$\frac{\text { Carbon } 5}{\text { Carbon } 2(42 \mathrm{~h})}$} & \multirow{2}{*}{$\frac{\text { Carbon } 2(42 \mathrm{~h})}{\text { Urinary water }}$} & \multirow{2}{*}{$\frac{\text { Carbon } 2}{\text { Carbon } 2(42 \mathrm{~h})}$} & \multirow{2}{*}{$\frac{\text { Carbon } 6}{\text { Carbon } 2(42 \mathrm{~h})}$} \\
\hline & & & & & \\
\hline & $h$ & & & & \\
\hline \multirow[t]{3}{*}{$\mathrm{EF}$} & 14 & 0.39 & 1.03 & 0.91 & 0.25 \\
\hline & 22 & 0.62 & & 0.92 & 0.40 \\
\hline & 42 & 0.91 & 1.05 & 1.00 & 0.74 \\
\hline \multirow[t]{3}{*}{ TA } & 14 & 0.63 & & 0.86 & 0.41 \\
\hline & 22 & 0.79 & & 0.95 & 0.54 \\
\hline & 42 & 0.99 & 0.99 & 1.00 & 0.72 \\
\hline \multirow[t]{3}{*}{ CS } & 14 & 0.63 & 0.90 & 0.91 & 0.41 \\
\hline & 22 & 0.78 & & 0.93 & 0.53 \\
\hline & 42 & 0.84 & 0.94 & 1.00 & 0.70 \\
\hline \multirow[t]{3}{*}{ MB } & 14 & 0.53 & & 0.86 & 0.39 \\
\hline & 22 & 0.81 & & 0.93 & 0.54 \\
\hline & 42 & 0.93 & & 1.00 & 0.73 \\
\hline \multirow[t]{3}{*}{$\mathrm{AM}$} & 14 & 0.33 & & 0.89 & 0.22 \\
\hline & 22 & 0.53 & & 0.98 & 0.37 \\
\hline & 42 & 1.00 & & 1.00 & 0.70 \\
\hline \multirow[t]{3}{*}{$\mathrm{HH}$} & 14 & 0.36 & 1.00 & 0.99 & 0.25 \\
\hline & 22 & 0.66 & & 1.02 & 0.47 \\
\hline & 42 & 0.93 & 0.99 & 1.00 & 0.64 \\
\hline \multirow[t]{3}{*}{$\mathrm{JC}$} & 14 & 0.49 & 1.09 & 0.71 & 0.36 \\
\hline & 22 & 0.71 & & 0.89 & 0.49 \\
\hline & 42 & 0.96 & 1.04 & 1.00 & 0.75 \\
\hline \multirow[t]{3}{*}{ EL } & 14 & 0.53 & 0.98 & 0.97 & 0.36 \\
\hline & 22 & 0.60 & & 0.95 & 0.39 \\
\hline & 42 & 0.93 & 1.02 & 1.00 & 0.66 \\
\hline \multirow[t]{3}{*}{ Mean \pm standard error } & 14 & $0.49 \pm 0.04$ & $1.00 \pm 0.03$ & $0.89 \pm 0.03$ & $0.33 \pm 0.03$ \\
\hline & 22 & $0.69 \pm 0.04$ & & $0.95 \pm 0.01$ & $0.47 \pm 0.03$ \\
\hline & 42 & $0.94 \pm 0.02$ & $1.01 \pm 0.02$ & 1.00 & $0.71 \pm 0.01$ \\
\hline
\end{tabular}

then bear no ${ }^{2} \mathrm{H}$ at carbons 2, thus resulting in an underestimation of the contribution of glycogenolysis. Correcting for that glucose increases the contribution of glycogenolysis at $14 \mathrm{~h}$ from $51 \%$ to $[(51+5) / 105] 100=53 \%$ with the contribution of gluconeogenesis reduced to $47 \pm 4 \%$. The corrected contributions of gluconeogenesis are then $67 \pm 4 \%$ at $22 \mathrm{~h}$ and $93 \pm 2 \%$ at $42 \mathrm{~h}$.

The enrichment in urinary water collected at $14-18 \mathrm{~h}$ was the same, $\sim 0.5 \%$, as at $38-42 \mathrm{~h}$, as expected from the amounts and times of ${ }^{2} \mathrm{H}_{2} \mathrm{O}$ administrations. That agrees with our previous experience under the same conditions. Thus, a constant enrichment in urinary water was achieved by $14 \mathrm{~h}$ and presumably for several hours before, since the last dose of ${ }^{2} \mathrm{H}_{2} \mathrm{O}$ was ingested $9 \mathrm{~h}$ into the fast.

In the conversion of fructose-6-P to glucose-6-P during gluconeogenesis, there is labeling at carbon 2 of the glucose-6-P through an exchange with water. Exchange resulting in labeling at carbon 2 of glucose-6-P formed by glycogenolysis depends upon the extent the glucose-6-P is converted to fructose-6-P before its conversion to glucose. When $\left(2-{ }^{3} \mathrm{H}, 2-{ }^{14} \mathrm{C}\right)$ galactose was infused into subjects fasted overnight, the ${ }^{3} \mathrm{H} /{ }^{14} \mathrm{C}$ ratio in blood glucose was $\sim 20 \%$ of that in the galactose, suggesting that in gluconeogenesis $\sim 80 \%$ of the hydrogen at carbon 2 equilibrates with water (2). In addition to exchange with water, interconversion of glucose-6-P with fructose-6-P occurs with hydrogen transfer, the intramolecular movement of hydrogen between carbons 1 and 2 of the hexose-6-phosphates (16). Intramolecular movement of the hydrogen bound to carbon 2 of glucose-6-P formed in glycogenolysis began with a hydrogen unenriched in deuterium. However, movement of the hydrogen bound to carbon 1 of fructose-6-P formed by gluconeogenesis began with a hydrogen already enriched to the extent of the hydrogens bound to carbon 6 . That is because the four hydrogens bound to carbons 1 and 6 of the fructose-6-P derive from the hydrogens bound to carbon 3 of the triose phosphates. That the hydrogen bound to carbon 2 of glucose-6-P formed from fructose-6-P by gluconeogenesis reached the enrichment in body water is evidenced by the absence of a discernible difference between the enrichment at carbon 2 at $42 \mathrm{~h}$ and the enrichment in urinary water.

The lower ratio of enrichment at carbon 2 at 14 and $22 \mathrm{~h}$ to that at $42 \mathrm{~h}$ then provides a measure of the extent of the equilibration of the hydrogen at carbon 2 of glucose-6-P with that in water during glycogenolysis. Since the mean ratio at 14-42 $\mathrm{h}$ was 0.89 when there was $53 \%$ glycogenolysis, the extent of equilibration was $[(89-47) / 53] 100=79 \%$. At $22 \mathrm{~h}$ it was $[(95-$ $67) / 33] 100=85 \%$. We do not know why we did not find lower enrichments at carbon 2 at $14 \mathrm{~h}$ than at $42 \mathrm{~h}$ in our previous study (1), when assaying enrichment by transferring the hydrogen at carbon 2 to lactate.

The proportions of gluconeogenesis calculated from the ratios at carbon 6 to carbon 2 at $42 \mathrm{~h}$ were $33 \pm 3 \%$ at $14 \mathrm{~h}$, 
$47 \pm 3 \%$ at $22 \mathrm{~h}$, and $71 \pm 1 \%$ at $42 \mathrm{~h}$. These percentages are in agreement with those previously reported under the same conditions (1), except then the percentages at 14 and $22 \mathrm{~h}, 35 \pm 2 \%$ and $38 \pm 2 \%$, were not significantly different. The differences in the rate of gluconeogenesis calculated from the $6 / 2$ ratio to that from the $5 / 2$ ratio is $16 \%$ at $14 \mathrm{~h}, 22 \%$ at $22 \mathrm{~h}$, and $23 \%$ at $42 \mathrm{~h}$. Those differences are due to the sum of incomplete equilibration of the hydrogens that become those bound to carbon 6 of the glucose in the process of gluconeogenesis and the contribution of glycerol to gluconeogenesis. Equilibration with body water after an overnight fast has been estimated to be $\sim 80 \%$ from the finding that on infusing $\left(3-{ }^{3} \mathrm{H}, 3-{ }^{14} \mathrm{C}\right)$ lactate the ${ }^{3} \mathrm{H} /{ }^{14} \mathrm{C}$ ratio in glucose was $\sim 0.2$ of that in the lactate $(1$, $2)$. The contribution of glycerol to glucose production has been estimated to be $\sim 3 \%$ after an overnight fast (17) and $10 \%$ after $60 \mathrm{~h}$ of fasting (18). At $42 \mathrm{~h}$ then $94-10=84 \%$ would have been the rate estimated from the $6 / 2$ ratio if equilibration had been complete. Therefore $(71 / 84) 100=85 \%$ was the extent of that equilibration. At $14 \mathrm{~h}$ the equilibration calculates to $[33 /(49-3)] 100=72 \%$.

\section{Discussion}

Almost all of glucose production after $42 \mathrm{~h}$ of fasting would be expected to be via gluconeogenesis. The estimate of $93 \%$ fulfills that expectation. Consistent with a $7 \%$ contribution of glycogenolysis is the rate of glycogenolysis suggested to occur in individuals at $40 \mathrm{~h}$ of fasting, from estimates of declines in hepatic glycogen content $(19,20)$. The $7 \%$ difference between the enrichment at carbon 5 and that in water at $42 \mathrm{~h}$ could be due in part or completely to an isotope effect. If so, the contributions of gluconeogenesis would be underestimated at the most by $3 \%$ at $14 \mathrm{~h}$. Evidence for the absence of an isotope effect is found on incubation of hepatocytes with lactate in the presence of ${ }^{3} \mathrm{H}_{2} \mathrm{O}$ and measurement of ${ }^{3} \mathrm{H}$ at carbon 2 and carbons 3, 4, and 5 of the glucose formed (21), measurement of ${ }^{3} \mathrm{H}$ at carbon 2 of glucose on giving fasted rats ${ }^{3} \mathrm{H}_{2} \mathrm{O}$ (22), and measurement of enrichment at carbon 5 of glucose on giving rats ${ }^{2} \mathrm{H}_{2} \mathrm{O}$ (23). The similar enrichment at carbon 2 and water at $42 \mathrm{~h}$ is also good evidence for a lack of discrimination in labeling at carbon 2 .

We have considered trivial the extent glucose released from the branch points experiences glucose cycling, i.e., formation of glucose-6-P from the glucose and concomitant hydrolysis to glucose, during which ${ }^{2} \mathrm{H}$ would be bound to the hydrogen at carbon 2. Cycling has been reported to be $11-20 \%$ of glucose production after an overnight fast (24-28). ${ }^{2}$ That would reduce the glucose formed from glycogen, without experiencing glucose-6-P formation, from perhaps 10 to $8 \%$. At $8 \%$ the corrected values would remain essentially unchanged, e.g., at $14 \mathrm{~h}[(51+4) / 104] 100=53 \%$. No significant cycling between glucose-6-P and triose-P after an overnight fast was found in one study (24), but was estimated to be $13 \%$ of glucose-6-P conversion to glucose in another study (31). Glucosyl units of glycogen converted to glucose-6-P in the process of glycogenolysis and experiencing that cycling, as well as fructose-6-P formed from glycogen and subjected to the transaldolase exchange reaction (7), would be included in the fraction of

2. Wolfe and associates $(29,30)$ reported cycling rates $>60 \%$, but those rates have not been confirmed in other investigations. glucose formed by gluconeogenesis. Thus, if cycling were $13 \%$, an estimate of $50 \%$ gluconeogenesis would reduce to $43.5 \%$. We have assumed there was sufficient turnover of glucose, after the enrichment in water reached steady state, so that the lower enrichment at carbon 2 at 14 than $42 \mathrm{~h}$ was due to incomplete isotopic equilibration at the hexose-6-P level. Alternatively, there was insufficient turnover of glucose. Then as a maximum, assuming complete equilibration, percent gluconeogenesis at $14 \mathrm{~h}$ from ratio of enrichment at carbon 5 to that carbon 2 at $14 \mathrm{~h}$, would be $56 \%$ rather than $47 \%$. Similarly at $22 \mathrm{~h}$, percent gluconeogenesis would be $73 \%$. If equilibration of dihydroxyacetone-3-P with glyceraldehyde-3-P was $90 \%$ complete $(3,32)$, by assuming it was complete, with glycerol's contribution to gluconeogenesis $10 \%$, the contribution of gluconeogenesis would be underestimated by $1 \%$. These considerations in total should affect the estimates very little.

Determinations of the contribution of gluconeogenesis to glucose production in healthy subjects after an overnight fast have ranged from 25 to $70 \%(19,33-41)$. That spread may be attributed in part to dietary preparation, but even with the same preparation, there has been marked variation in glycogen stores at the beginning of fasting (34). Several of the estimates required a number of uncertain assumptions or the method has been shown to be invalid (42-44). Measurements of net splanchnic exchange of glucose and precursor substrates give contributions after an overnight fast from $25-35 \%$ (39-41) and after $60 \mathrm{~h}$ of fasting $85-90 \%(39,45,46)$. While these estimates are somewhat lower than present estimates, splanchnic net balance calculations do not account for hepatic uptake of substrates formed within the splanchnic bed, e.g., gut release of lactate or amino acids (47), nor do they allow for splanchnic extrahepatic glucose utilization and the contribution by kidney to glucose production (48). Estimates from incorporation of label from a labeled gluconeogenic substrate, e.g., lactate or alanine, are uncertain because of dilution of label in the Krebs cycle and the need to estimate the enrichment or specific activity of pyruvate in liver (43). Our method eliminated those uncertainties, since ${ }^{2} \mathrm{H}$ is incorporated for each molecule of gluconeogenic substrate converted to glucose and the enrichment of the ${ }^{2} \mathrm{H}$ is that in body water.

Shulman and associates $(19,34)$ estimated gluconeogenic rates by determining the rate of glycogenolysis, using NMR to measure hepatic glycogen content and MRI to measure liver volume. They then subtracted the rate of glycogenolysis from the rate of glucose production, measured from glucose kinetics using $\left(6-{ }^{3} \mathrm{H}\right)$ glucose. Gluconeogenesis was calculated to account for $\sim 65 \%$ of glucose production during the first $22 \mathrm{~h}$ of fasting, $82 \%$ during the next $24 \mathrm{~h}$ of fasting, and $96 \%$ from $46-$ $64 \mathrm{~h}$ of fasting, in good agreement with our estimates. However, they found the rate of gluconeogenesis to be linear over the first $22 \mathrm{~h}$ of fasting. Recently, they estimated gluconeogenesis contributes $\sim 50 \%$ to glucose production during the first $12 \mathrm{~h}$ of fasting (49). If the concentration of hepatic glycogen regulates its rate of breakdown (50), a greater amount of glycogenolysis might be expected in the earlier hours of fasting. Their method measures glucose production from liver and to the extent it occurs from kidney (48), while measuring glycogenolysis from liver. The contribution of gluconeogenesis is not measured directly, but rather depends on an estimate of the difference in hepatic glycogen content (51) at some distance in time and the accuracy of the glucose production measurement. The ${ }^{2} \mathrm{H}_{2} \mathrm{O}$ method measures the contribution of glu- 
coneogenesis whether from liver or kidney, since each glucose produced, if formed via gluconeogenesis, bears label at carbons 2 and 5 and via glycogenolysis at carbon 2 .

Infusing ${ }^{13} \mathrm{C}$-labeled lactate, Lee et al. (37), using mass isotopomer distribution analysis, reported gluconeogenic contributions of $39-50 \%$ in three subjects after an overnight fast and of $71 \%$ in one subject after a 24 -h fast. Infusing ${ }^{13} \mathrm{C}$-labeled glycerol, Hellerstein et al. (38) estimated gluconeogenic contributions after an overnight fast of $30-40 \%$. Estimates using mass isotopomer distribution analysis require the assumption of a single pool of triose-P from which the glucose is formed or multiple pools with similar enrichments of ${ }^{13} \mathrm{C}(3)$. Infusing relatively small quantities of $\left[\mathrm{U}^{13} \mathrm{C}\right]$ glycerol, after many hours of fasting, the assumption apparently was not fulfilled (3). With higher quantities it apparently was, at least in the rat $(32,52)$, although infusing those quantities could alter gluconeogenic rates and under different conditions the requirement of a single enriched pool or its equivalent might not be achieved. With the ${ }^{2} \mathrm{H}_{2} \mathrm{O}$ method all pools presumably experience the enrichment of body water.

An assumption in the ${ }^{2} \mathrm{H}_{2} \mathrm{O}$ method is that glycogen cycling, i.e., simultaneous glycogen synthesis and breakdown, does not compromise the estimates. The extent of cycling, if any, in liver in the fasting state has not been measured. We estimated glycogen cycling to be minimal after giving a glucose load (53). After giving a larger load, cycling was estimated to be much higher in particular in subjects who ingested a high carbohydrate diet (50). Only if the glucose-6-P synthesized by gluconeogenesis was deposited, and if in its place an unlabeled glucosyl unit was released as glucose, and in the process labeling occurred at carbon 2, would glycogenolysis be concluded in the face of no change in glycogen content. This would not occur as long as last deposited is first removed $(54,55)$. If labeled glucose formed at an early time during fasting was deposited in glycogen and impacted on the labeling of blood glucose released from glycogen at a later time during the fast, previous results (1) would have been expected to be different. The carbon 6 to carbon 2 ratio we found in blood glucose drawn $14 \mathrm{~h}$ into a fast and $4 \mathrm{~h}$ after giving $\mathrm{D}_{2} \mathrm{O}$, while the subjects were few in number, should have been different than the ratio in blood glucose drawn $14 \mathrm{~h}$ into a fast and $9 \mathrm{~h}$ after giving $\mathrm{D}_{2} \mathrm{O}$. Our estimates of gluconeogenesis in agreement with those reported using NMR also suggest glycogen cycling were not a factor. If glucose-6-P synthesized by gluconeogenesis is converted to glycogen and then released, it is calculated as glucose produced by gluconeogenesis.

In conclusion, rates of gluconeogenesis can be measured safely by the ${ }^{2} \mathrm{H}_{2} \mathrm{O}$ method using enrichments at carbons 2 and 5 of blood glucose and in urinary water. At steady state the ratio of enrichment at carbon 5 to urinary water is directly the fraction of glucose formed via gluconeogenesis. Not at steady state, the fraction is the ratio of enrichment at carbon 5 to carbon 2 with correction to the enrichment at carbon 2 for reactions within the course of glycogenolysis. After an overnight fast gluconeogenesis accounts for $\sim 50 \%$ of glucose production, increases by $22 \mathrm{~h}$, and by $42 \mathrm{~h}$ of fasting accounts for almost all of glucose production in healthy subjects.

\section{Acknowledgments}

We gratefully acknowledge the excellent technical assistance of Lourdes Gruca.
This study was supported by National Institutes of Health grants DK-14507 and P50 HD-11089 and grant 89-0418 from the Bank of Sweden Tercentenary Foundation.

\section{References}

1. Landau, B.R., J. Wahren, V. Chandramouli, W.C. Schumann, K. Ekberg, and S.C. Kalhan. 1995. Use of ${ }^{2} \mathrm{H}_{2} \mathrm{O}$ for estimating rates of gluconeogenesis. $J$. Clin. Invest. 95:172-178.

2. Wajngot, A., V. Chandramouli, W.C. Schumann, K. Kumaran, S. Efendic, and B.R. Landau. 1989. Testing of the assumptions made in estimating the extent of futile cycling. Am. J. Physiol. 256:E668-E675.

3. Landau, B.R., C.A. Fernandez, S.F. Previs, K. Ekberg, V. Chandramouli, J. Wahren, S.C. Kalhan, and H. Brunengraber. 1995. A limitation in the use of mass isotopomer distributions to measure gluconeogenesis in fasting humans. Am. J. Physiol. 269:E18-E26.

4. Williamson, D.H., and J. Mellanby. 1974. D-(-)-3-Hydroxybutyrate. In Methods of Enzymatic Analysis. H.U. Bergmeyer, editor. Verlag Chemie International, Deerfield Beach, FL. 1836-1839.

5. Sowden, J.C. 1951. Preparation of 1-C ${ }^{14}-\mathrm{D}-\mathrm{xylose}$ from 1-C $\mathrm{C}^{14}$-D-glucose. J. Am. Chem. Soc. 73:5496-5497.

6. Dische, Z., and E. Borenfreund. 1957. A new color reaction for the determination of aldopentose in the presence of other saccharides. Biochim. Biophys. Acta. 23:639-642.

7. Ljungdahl, L., H.G. Wood, E. Racker, and D. Couri. 1961. Formation of unequally labeled fructose-6-phosphate by an exchange reaction catalyzed by transaldolase. J. Biol. Chem. 236:1622-1625.

8. Kalhan, S.C., S.M. Savin, and P.A.J. Adam. 1977. Estimation of glucose turnover with stable tracer glucose-1-13 C. J. Lab. Clin. Med. 89:285-294.

9. Schäffer, L., and B. Tronier. 1989. Enzymatic determination of $1-{ }^{14} \mathrm{C}$-glucose in pig plasma. Diabetologia. 32:660-662.

10. Baddiley, J., J.G. Buchanan, B. Carss, and A.P. Mathias. 1956. Cytidine diphosphate ribitol from Lacobacillus arabinosus. J. Chem. Soc. 4583-4588.

11. Stetten, M.R., and J.J. Kehoe. 1971. Synthesis of D-ribitol-5-phosphate by an inorganic pyrophosphate-ribitol phosphotransferase activity of microsomal glucose-6-phosphatase. Biochim. Biophys. Acta. 250:501-513.

12. Crane, R.K., and F. Lipmann. 1953. The effect of arsenate on aerobic phosphorylation. J. Biol. Chem. 201:235-253.

13. Reeves, R.E. 1941. The estimation of primary carbinol groups in carbohydrates. J. Am. Chem. Soc. 63:1476-1477.

14. Kalhan, S.C., R. Trivedi, S. Singh, V. Chandramouli, W.C. Schumann, and B.R. Landau. 1995. A micromethod for measurement of deuterium bound to carbon 6 of glucose to quantify gluconeogenesis in-vivo. J. Mass. Spec. 30: $1588-1592$.

15. Jackson, E.L. 1944. Periodic acid oxidation. Org. React. 2:341-375.

16. Rose, I.A., and E.L. O'Connell. 1961. Intramolecular hydrogen transfer in the phosphoglucose isomerase reaction. J. Biol. Chem. 236:3086-3092.

17. Nurjhan, N., A. Consoli, and J. Gerich. 1992. Increased lipolysis and its consequences on gluconeogenesis in non-insulin-dependent diabetes mellitus. J. Clin. Invest. 89:169-175.

18. Wahren, J., S. Efendic, R. Luft, L. Hagenfeldt, O. Bjorkman, and P. Felig. 1977. Influence of somatostatin on splanchnic glucose metabolism in postabsorptive and 60-h fasted humans. J. Clin. Invest. 59:299-307.

19. Rothman, D.L., I Magnusson, R.G. Shulman, and G.I. Shulman. 1991. Quantitation of hepatic glycogenolysis and gluconeogenesis in fasting humans with ${ }^{13}$ C NMR. Science (Wash. DC). 254:573-576.

20. Nilsson, L.H., and E. Hultman. 1973. Liver glycogen in man: the effect of total starvation or a carbohydrate poor diet followed by carbohydrate refeeding. Scand. J. Clin. Lab. Invest. 32:325-330.

21. Rognstad, R., D.G. Clark, and J. Katz. 1974. Glucose synthesis in tritiated water. Eur. J. Biochem. 47:383-388.

22. Kuwajima, M., S. Golden, J. Katz, R.H. Unger, D.W. Foster, and J.D. McGarry. 1986. Active hepatic glycogen synthesis from gluconeogenic precursors despite high tissue levels of fructose 2, 6-bisphosphate. J. Biol. Chem. 261: 2632-2637.

23. Guo, Z.K., W.-N.P. Lee, J. Katz, and A.E. Bergner. 1992. Quantitation of positional isomers of deuterium-labeled glucose by gas chromotography/ mass spectrometry. Anal. Biochem. 204:273-282.

24. Karlander, S., A. Roovete, M. Vranic, and S. Efendic. 1986. Glucose and fructose-6-P cycle in humans. Am. J. Physiol. 251:E530-536.

25. Karlander, S., A. Khan, A. Wajngot, O. Torring, M. Vranic, and S. Efendic. 1989. Glucose turnover in hyperthyroid patients with normal tolerance. J. Clin. Endocrinol. \& Metab. 68:780-786.

26. Buttler, P., and R. Rizza. 1991. Contributions to postprandial hyperglycemia and effect on splanchnic glucose clearance of hepatic glucose cycling in glucose intolerant or NIDDM patients. Diabetes. 40:73-81.

27. Calles-Escandon, J. 1994. Insulin dissociates hepatic glucose cycling and glucagon-induced thermogenesis in man. Metab. Clin. Exp. 43:1000-1005.

28. Rooney, D.P., R.D.G. Neely, C. Cullen, C.N. Ennis, B. Sheridan, A.B. Atkinson, E.R. Trimble, and P.M. Bell. 1993. The effect of cortisol on glucose/ glucose-6-phosphate cycle activity and insulin action. J. Clin. Endocrinol. \& 
Metab. 77:1180-1183.

29. Shulman, G.I., P.W. Ladenson, M.H. Wolfe, E.C. Ridgeway, and R.R. Wolfe. 1985. Substrate cycling between gluconeogenesis and glycolysis in euthyroid, hypothyroid and hyperthyroid man. J. Clin. Invest. 76:757-764.

30. Miyoshi, H., G.I. Shulman, E.J. Peters, M.H. Wolfe, D. Elahi, and R.R. Wolfe. 1988. Hormonal control of substrate cycling in humans. J. Clin. Invest. 81:1545-1555

31. Magnusson, I., A. Wennlund, V. Chandramouli, W.C. Schumann, K. Kumaran, J. Wahren, and B.R. Landau. 1990. Fructose-6-phosphate cycling and the pentose cycle in hyperthyroidism. J. Clin. Endocrinol. \& Metab. 70:461466.

32. Neese, R A. J-M. Schwarz, D. Faix, S. Turner, A Letscher, D. Vu, and M.K. Hellerstein. 1995. Gluconeogenesis and intrahepatic triose phosphate flux in response to fasting or substrate loads. J. Biol. Chem. 270:14452-14463.

33. Consoli, A., F.P. Kennedy, J. Miles, and J.E. Gerich. 1987. Determination of Krebs cycle metabolic carbon exchange in vivo and its use to estimate individual contributions of gluconeogenesis and glycogenolysis to overall output in man. J. Clin. Invest. 80:1303-1310.

34. Magnusson, I., D.L. Rothman, L.D. Katz, R.G. Shulman, and G.I. Shulman. 1992. Increased rate of gluconeogenesis in type II diabetes mellitus. $J$. Clin. Invest. 90:1323-1327.

35. Pimenta, W., N. Nurjhan, P.A. Jansson, M. Stumvoll, J. Gerich, and M. Korytkowski. 1994. Glycogen: its mode of formation and contribution to hepatic glucose output in postabsorptive humans. Diabetologia. 37:697-709.

36. Gay, L.J., Ph. Schneiter, Y. Schutz, E. Di Vetta, E. Jequier, and L. Tappy. 1994. A non-invasive assessment of hepatic glycogen kinetics and postabsorptive gluconeogenesis in man. Diabetologia. 37:517-523.

37. Lee, W.P., S. Bassilian, E.A. Bergner, P. Wals, and J. Katz. 1994. Mass isotopomer study of gluconeogenesis with ${ }^{13} \mathrm{C}$ labeled lactate in man. Clin. Res. 42:28A.

38. Hellerstein, M., R. Neese, P. Linfoot, M. Christiansen, and S. Turner. 1995. Contribution from gluconeogenesis (GNG) to fasting blood glucose measured by mass isotopomer distribution analysis (MIDA) in normal humans. $\mathrm{Di}$ abetes. 44:153A.

39. Bratusch-Marrain, P., O. Björkman, L. Hagenfeldt, W. Waldhäusl, and J. Wahren. 1979. Influence of arginine on splanchnic glucose metabolism in man. Diabetes. 28:126-131.

40. Björkman, O., R. Gunnarsson, E. Hagström, P. Felig, and J. Wahren. 1989. Splanchnic and renal exchange of infused fructose in insulin-deficient type I diabetic patients and healthy controls. J. Clin. Invest. 83:52-59.

41. Wahren, J., A. Wennlund, L.H. Nilsson, and P. Felig. 1981. Influence of hyperthyroidism on splanchnic exchange of glucose and gluconeogenic precur- sors. J. Clin. Invest. 67:1056-1063.

42. Chiasson, J.L., L. Lijenquist, W.W. Lacy, A. Jennings, and A.D. Cherrington. 1977. Gluconeogenesis. Methodologic approaches in vivo. Fed. Proc. 36:229-235.

43. Landau, B.R. 1993. Estimating gluconeogenic rates in NIDDM. $A d v$. Exp. Med. Biol. 334:209-220.

44. Schumann, W.C., I. Magnusson, V. Chandramouli, K. Kumaran, J. Wahren, and B.R. Landau. 1991. Metabolism of $\left(2{ }^{14} \mathrm{C}\right)$ acetate and its use in assessing hepatic Krebs cycle activity and gluconeogenesis. J. Biol. Chem. 266: 6985-6990.

45. Björkman, O., P. Felig, and J. Wahren. 1986. The role of basal glucagon levels in the regulation of splanchnic glucose output and ketogenesis in insulindeficient humans after an overnight and $60 \mathrm{hr}$ fast. Clin. Physiol. 4:227-241.

46. Björkman, O., P. Felig, and J. Wahren. 1980. The contrasting responses of splanchnic and renal glucose output to gluconeogenic substrate administration and hypoglucagonemia in 60-h-fasted humans. Diabetes. 29:610-616.

47. Björkman, O., L.S. Eriksson, B. Nyberg, and J. Wahren. 1990. Gut exchange of glucose and lactate in basal state and after oral glucose ingestion in postoperative patients. Diabetes. 39:747-751.

48. Stumvoll, M., U. Chintalapudi, G. Perriello, S. Welle, O. Gutierez, and J. Gerich. 1995. Uptake and release of glucose by human kidney. J. Clin. Invest. 96:2528-2533.

49. Petersen, K.F., T. Price, G.W. Cline, D.L. Rothman, and G.I. Shulman. 1996. Contribution of net hepatic glycogenolysis to glucose production during the early postprandial period. Am. J. Physiol. 270:E186-E191.

50. Magnusson, I., D.L. Rothman, B. Jucker, G.W. Cline, R.G. Thulman, and G.I. Shulman. 1994. Liver glycogen turnover in fed and fasted humans. Am. J. Physiol. 266:E796-E803.

51. Gruetter, R., I. Magnusson, D.L. Rothman, M.J. Avison, R.G. Shulman, and G.I. Shulman. 1994. Validation of ${ }^{13} \mathrm{C}$ NMR measurements of liver glycogen in vivo. Magn. Reson. Med. 31:583-588.

52. Peroni, O., V. Large, and M. Beylot. 1995. Measuring gluconeogenesis with $\left(2-{ }^{13} \mathrm{C}\right)$ glycerol and mass isotopomer distribution analysis of glucose. Am. J. Physiol. 269:E516-E523.

53. Wajngot, A., V. Chandramouli, W.C. Shumann, S. Efendic, and B.R. Landau. 1991. Quantitation of glycogen/glucose-1-P cycling in liver. Metab. Clin. Invest. 40:877-881.

54. Landau, B.R., J.R. Leonards, and F.M. Barry. 1960. A quantitative study of glucagon-induced hepatic glycogenolysis. Am. J. Physiol. 199:231-234.

55. Goodwin, G.W., J.R. Arteaga, and H. Taegtmeyer. 1995. Glycogen turnover in the isolated working heart. J. Biol. Chem. 270:9234-9240. 